\title{
Evaluation of Third-party Reverse Logistics Providers Based on Extension Superiority Method
}

\author{
Bingkun Dong ${ }^{1}$, Xiaoning Zhu' ${ }^{*}$, Rui Yan ${ }^{1}$, Changlu Zhang ${ }^{2}$ \\ ${ }^{1}$ Donlinks School of Economics and Management, University of Science \& Technology Beijing, Beijing 100083, China \\ ${ }^{2}$ School of Economics and Management, Beijing Information Science \& Technology University, Beijing 100192, China
}

Corresponding Author Email: zhuxiaoning@ustb.edu.cn

https://doi.org/10.18280/isi.240115

Received: 19 December 2018

Accepted: 10 January 2019

\author{
Keywords: \\ third-party reverse logistics (3PRL) \\ providers, evaluation index system, \\ extension superiority method (ESM)
}

\begin{abstract}
Reverse logistics, the future of logistics and supply chain, can save operating cost, improve ecological benefits and create a good image of production companies. Since many companies choose to outsource reverse logistics to third-party providers, it is important to evaluate and select third-party reverse logistics (3PRL) providers in a rational manner. For this purpose, this paper establishes an evaluation index system with nine indices on three factors of provider capability: strength factor, service level and development potential. Then, the extension superiority method (ESM) was adopted to set up an evaluation model, transforming the multiindex decision-making problem into a single-objective evaluation task. Finally, the feasibility and effectiveness of our index system and evaluation model were verified through an empirical study on a Chinese tobacco company and its 3PRL provider.
\end{abstract}

\section{INTRODUCTION}

The global consumption upgrade, coupled with growing resource, energy and environmental pressures [1], has promoted a series of logistics activities, such as waste recycling, return of goods and product recall. All these activities belong to reverse logistics, a new field of logistics and supply chain research. As an indispensable part of the supply chain system, reverse logistics has attracted much attention from the business and the academia, thanks to its abilities to conserve resource energy and mitigate environmental pollution.

Reverse logistics inherits some features of traditional logistics modes, namely, the abundance of manpower and information. Meanwhile, this emerging logistics mode has its own features like low value density and high technical requirements. Therefore, many companies, facing capital, technology and cost constraints or limited by strategic arrangements, prefer outsourcing reverse logistics activities to third-party providers to self-operated reverse logistics. In this way, the value density of reverse logistics can be increased due to the intensive advantages of third-party reverse logistics (3PRL) providers. Thus, the entrusting company needs to evaluate and select 3PRL providers in a scientific and reasonable manner. This calls for an effective index system and a proper method for evaluation of 3PRL providers.

The relevant research can be divided into two parts, namely, the construction of the index system and the selection of the evaluation method. Concerning index system construction, Ma L. and $\mathrm{Wu} \mathrm{N}$. set up a relatively complete index system covering such aspects as management level, service level, technical operation level, informatization level and social ecological benefit [2-3]. Cao L. built an index system for the 3PRL of the home appliance industry, which consists of 20 indices on strength, service, development potential and alliance [4]. Yue H. et al. established a 3PRL evaluation index system of 27 indices on management level, technical strength, informatization level, transport capacity, coordination ability and cost factor [5].

Concerning evaluation method, scholars at home and abroad have adopted the following approaches separately or simultaneously: analytic hierarchy process (AHP), fuzzy comprehensive evaluation (FCE), entropy weight method, the technique for order of preference by similarity to ideal solution (TOPSIS) method, quality function deployment (QFD). For example, Liu Q.S. et al. combined the gradient index (GI) and entropy weight to evaluate a 3PRL provider [6]. Li J. et al. relied on questionnaire survey and interview to identify the seven aspects of consumer demand, and evaluated 3PRL providers by fuzzy QFD [7]. Chen K.J. integrated the analytic network process (ANP) with entropy weight to select 3PRL providers [8]. Li Z.P. et al. conducted TOPSIS-based evaluation of the third-party providers of reverse logistics services [9].

Despite their fruitful results and wide application, the existing studies have some common defects. For example, the AHP, the TOPSIS and the network analysis method are too subjective and over-dependent on expert opinions, the entropy method relies heavily on empirical data, producing counterintuitive results, while the fuzzy QFD only applies to consumer demand analysis. To solve these defects, this paper puts forward an evaluation method for 3PRL providers based on the extension superiority method (ESM). Meanwhile, the index system was constructed referring to the previous research results, with full consideration of the new features of 3PRL.

\section{CASE STUDIES}

\subsection{Evaluation method}

The ESM is an important evaluation method in the matterelement extension theory, which was proposed by Cai Wen in 
1983 to resolve contradictory problems. In this theory, the classical field and controlled field of the matter-element to be evaluated are obtained by determining the evaluation index; then, the matter-element is constructed according to the actual problem, followed by fitness calculation. Since its birth, the theory has been widely applied in the field of evaluation, such as coalmine safety assessment, urban low-carbon consumption evaluation and appraisal of logistics providers [10-12].

In this paper, the ESM is employed to evaluate 3PRL providers, because this method can eliminate the incompatibility between subjective and objective indices and output reasonable results in line with our cognitive habits. Firstly, the classical field and controlled field of the matterelement to be evaluated were constructed based on the evaluation index system and capability grade; Secondly, the correlation function was determined to describe the relationship between the evaluation index system and the capability grade, and the weight of each index was calculated by the AHP; Finally, the fitness between the matter-element and the capability grade was acquired to capability grade of each 3PRL provider.

\subsection{Evaluation index system}

The existing evaluation index systems of 3PRL providers are relatively mature, involving complex and numerous indices. However, the selection of evaluation indices is not the more the better, but should follow certain principles.

\subsubsection{Index selection principles}

(1) Practicality

The index system must be scientific and correctly reflect the actual situation of the 3PRL providers. If there are too many indices on multiple levels, the evaluation will be difficult to perform and some key aspects of the providers might be overlooked. Hence, the index system should consist of indices that can effectively demonstrate the capability grade of 3PRL providers.

\section{(2) Systematicity}

The evaluation of 3PRL providers should cover multiple aspects, consider both the current grade and the potential of sustainable development, and strike a balance between cost efficiency and environmental protection. Therefore, the index system must be comprehensive enough to reveal the true capability of 3PRL providers.

(3) Clarity

The meaning of each evaluation index should be clearly defined, so do its measurement and data acquisition method.

\subsubsection{Index system establishment}

Following the above principles, the author established an index system for the entrusting company to evaluate its 3PRL providers. The evaluation indices were divided into three categories, namely, strength factor, service level and development potential, in reference to the previous research.

Specifically, the number of years engaging in reverse logistics, the number of provinces/countries covered by outlets and the mean turnover in the last 3 years were selected as indices of the strength of providers (Table 1). This is because the he longer a provider is involved in reverse logistics activities, the better its experience and service level; the denser the outlets, the higher the service level and the faster the response to consumer demand; the turnover is an effective indicator of a provider's financial strength.
Table 1. Indices on strength factor

\begin{tabular}{|c|c|c|}
\hline & Index & Meaning \\
\hline 1 & Experience & $\begin{array}{c}\text { The number of years engaging in reverse } \\
\text { logistics }\end{array}$ \\
\hline 2 & $\begin{array}{l}\text { Outlet } \\
\text { coverage }\end{array}$ & $\begin{array}{c}\text { The number of provinces/countries } \\
\text { covered by outlets }\end{array}$ \\
\hline 3 & $\begin{array}{l}\text { Financial } \\
\text { strength }\end{array}$ & The mean turnover in the last 3 years \\
\hline
\end{tabular}

The service level of 3PRL providers was described by three indices: service cost, service timeliness and complaint rate (Table 2). The service cost was selected because the entrusting company always wishes to enjoy the best service at the lowest cost; the service timeliness was selected for the providers must provide the logistics services in time under the constraint of low cost; the complaint rate is also important, as it directly reflect the past service level of the provider.

Table 2. Indices on service level

\begin{tabular}{|c|c|c|}
\hline & Index & Meaning \\
\hline 1 & Service cost & Charge for the same service item \\
\hline 2 & $\begin{array}{c}\text { Service } \\
\text { timeliness }\end{array}$ & $\begin{array}{c}\text { Timeliness compared to the mean level of } \\
\text { the industry }\end{array}$ \\
\hline 3 & Complaint rate & $\begin{array}{c}\text { The number of complaints per 10,000 } \\
\text { orders }\end{array}$ \\
\hline
\end{tabular}

The development potential of 3PRL providers is critical to the strategic alliance between the entrusting company and the providers in the long run. Here, this factor is evaluated against three indices: informatization level, R\&D rate and carbon emissions (Table 3). These indices were adopted due to the following reasons.

In recent years, there is a rapid development of nextgeneration information technologies, such as mobile Internet, cloud computing and artificial intelligence. Against this backdrop, the informatization level, a key to future reverse logistics, directly affects the 3PRL provider's ability to fulfil consumer demand timely and transparently in the context of big data. A high level of informatization is the prerequisite for real-time perception, fast transmission, large-capacity storage, intelligent processing and visual display of the logistics information.

The R\&D rate reflects the continued technical investment of each 3PRL provider, which is essential to maintaining longlasting technological advancement. After all, the reverse logistics, as an emerging industry, requires many special facilities, equipment and treatment methods to reduce the resource waste and improve waste recycling. Thus, the R\&D rate was calculated as the $R \& D$ investment per unit of turnover.

The carbon emissions per unit of output was taken as an index of the development potential because the social and ecological performance of 3PRL providers affect both the operating cost and the social image of the entrusting company.

Table 3. Indices on development potential

\begin{tabular}{|c|c|c|}
\hline & Index & Meaning \\
\hline 1 & $\begin{array}{c}\text { Informatization } \\
\text { level }\end{array}$ & $\begin{array}{c}\text { The informatization level compared } \\
\text { with average of the industry }\end{array}$ \\
\hline 2 & R\&D rate & $\begin{array}{c}\text { The R\&D investment per unit of } \\
\text { turnover }\end{array}$ \\
\hline 3 & Carbon emissions & $\begin{array}{c}\text { The carbon emissions per unit of } \\
\text { turnover }\end{array}$ \\
\hline
\end{tabular}


On this basis, our evaluation index system for 3PRL providers was established (Figure 1).

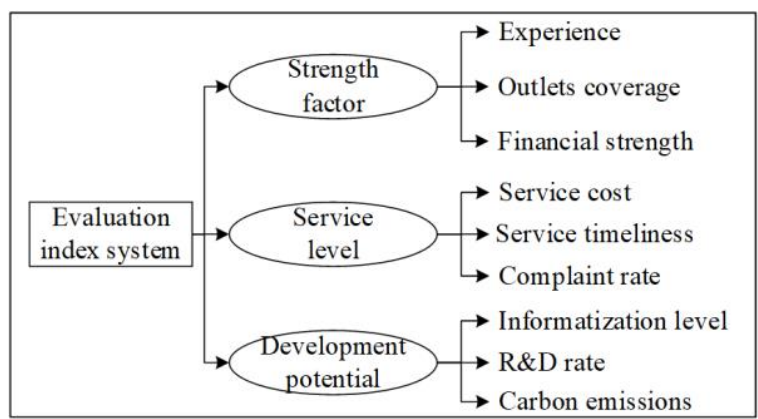

Figure 1. 3PRL provider evaluation index system

\subsection{Establishment of the evaluation model}

(1) Construction of feature units

Let $S I=\left\{S I_{1}, S I_{2}, S I_{3}, S I_{4}, S I_{5}, S I_{6}, S I_{7}, S I_{8}, S I_{9}\right\}$ be the set of feature units of a 3PRL provider. Each feature unit $\mathrm{SI}_{\mathrm{i}}$ can be expressed as $\left(\mathrm{c}_{\mathrm{i}}, \mathrm{v}_{\mathrm{i}}\right)$, with $\mathrm{c}_{\mathrm{i}}$ being the evaluation indices of provider capacity and $\mathrm{v}_{\mathrm{i}}$ being the value range of each index. Here, $c_{1} \sim c_{9}$ respectively refer to experience, outlet coverage, financial strength, service cost, service timeliness, complaint rate, informatization level, $R \& D$ rate and carbon emissions.

(2) Construction of matter-element model

By common sense, the provider capability was divided into four grades. The set of the four evaluation grades can be expressed as $Z=\left\{Z_{1}, Z_{2}, Z_{3}, Z_{4}\right\}$, where $Z_{1} \sim Z_{4} \quad\left(z_{j}(j=\right.$ $1,2,3,4))$ respectively represent the excellent level $(90 \sim 100)$, the good level $(80 \sim 90)$, the moderate level $(60 \sim 80)$ and the poor level $(0 \sim 60)$ in centesimal grade. On this basis, the matter-element model can be established as (Eq. 1):

$R_{j}=(Z, C, V)=\left[\begin{array}{ccc}Z_{j} & c_{1} & v_{1 j} \\ & c_{2} & v_{2 j} \\ & \cdots & \cdots \\ & c_{9} & v_{9 j}\end{array}\right]$

where $z_{j}(j=1,2,3,4)$ are the four grades of provider capability; $c_{i}(i=1,2 \cdots 9)$ are the nine indices; $v_{i j}$ is the value range of the $i$-th index on the $j$-th grade. Then, $R_{j}(j=$ $1,2,3,4)$ can constitute a matter-element aggregate with the same index system. Let $Q$ be the overall grade of provider capability. Then, the controlled field model can be built as (Eq. 2):

$R_{Q}=(Q, C, V)=\left[\begin{array}{ccc}Q & c_{1} & v_{1 q} \\ & c_{2} & v_{2 q} \\ & \cdots & \cdots \\ & c_{9} & v_{9 q}\end{array}\right]=\left[\begin{array}{ccc}Q & c_{1} & (0,100) \\ & c_{2} & (0,100) \\ \ldots & \ldots \\ & c_{9} & (0,100)\end{array}\right]$

where $v_{i q}$ stands for the overall value range of each evaluation index.

(3) Determination of index weights

Considering the different impacts of the evaluation indices on the overall grade, the weight of each index was determined by the AHP, laying the basis for fitness computation. Specifically, the indices were compared in pairs, and their importance was measured against the Likert 9-point scale. The judgement matrix was constructed by selected experts according to the AHP scoring rule. After that, the weights of the nine indices were computed by the eigenvector method. The results were subjected to the consistency test and only the acceptable ones were selected as the index weights. The weight vector can be expressed as (Eq. 3):

$\omega=\left(\omega_{1}, \omega_{2}, \cdots \omega_{9}\right)^{T}$

(4) Determination of correlation function and degree of correlation.

In extension theory, the correlation function to describe the degree of correlation of each index to different grades can be expressed as (Eq. 4):

$K_{j}\left(v_{i}\right)= \begin{cases}-\rho\left(v_{i}, V_{i j}\right) /\left|V_{i j}\right| & v_{i} \in V_{i j} \\ \frac{\rho\left(v_{i}, V_{i j}\right)}{\rho\left(v_{i}, V_{i q}\right)-\rho\left(v_{i}, V_{i j}\right)} & v_{i} \notin V_{i j}\end{cases}$

$(i=1,2, \cdots, 9 ; j=1,2,3,4)$

where $\rho\left(v_{i}, V_{i j}\right)=\left|v_{i}-\left(a_{i j}+b_{i j}\right) / 2\right|-\left(b_{i j}-a_{i j}\right) / 2$; $\rho\left(v_{i}, V_{i q}\right)=\left|v_{i}-\left(a_{i q}+b_{i q}\right) / 2\right|-\left(b_{i q}-a_{i q}\right) / 2 ;\left|V_{i j}\right|=$ $\left|a_{i j}-b_{i j}\right|$. Before fitness calculation, the obtained degrees of correlation should be normalized as (Eq. 5):

$k_{i j}=\frac{K_{j}\left(v_{i}\right)}{\max \left|K_{j}\left(v_{i}\right)\right|}$

(5) Fitness calculation and capability evaluation

The fitness calculation helps to determine the degree of correlation of the evaluation object to different grades with the ESM. The fitness of $R_{0}$ to $Z_{j}$ can be defined as (Eq. 6):

$C\left(Z_{j}\right)=\sum_{i=1}^{9} \lambda_{i} k_{i j}(j=1,2,3,4)$

As shown in the above formula, the fitness is the weighted sum of the degrees of correlations of each index to the capability grades. For example, $C\left(Z_{0}\right)=\max \left\{C\left(Z_{j}\right)\right\}$ means that the object belongs to the grade $Z_{0}$.

\section{EMPIRICAL RESEARCH}

Recent years has seen the stable development of the tobacco industry in China, the world's largest cigarette consumer, owing to the special "monopoly administration" system [13]. With the growing awareness of environmental protection, however, the tobacco industry must complete the transformation to green operations. This calls for lots of reverse logistics in the production and circulation of cigarette products. For example, the cigarette boxes should be recycled and reused, such as to reduce the cost and even create a profit source. The return of cigarettes is also a key to reverse logistics, which directly affects the profit level and competitiveness of the tobacco industry [14]. In general, cigarette companies prefer to outsource reverse logistics to third-party providers rather than operate reverse logistics independently. This is 
because outsourcing allows them to concentrate on core businesses like production and sales and realize high quality service at a low cost.

To verify the effectiveness of our evaluation method, an empirical research was carried out on the 3PRL provider (Company J) of a tobacco company (Company H) affiliated to China Tobacco. Company J was taken as the matter-element to be evaluated. Ten famous experts in charge of reverse logistics outsourcing in Company $\mathrm{H}$ were invited to rate the capability of Company $\mathrm{J}$ against our evaluation index system. The arithmetic mean of each expert's score is shown in Eq. 7 and Table 4. The matter-element model can be expressed as (Eq. 7):

$$
R_{0}=\left(P_{0}, C, V\right)=\left[\begin{array}{ccc}
P_{0} & c_{1} & v_{1} \\
& c_{2} & v_{2} \\
& \ldots & \ldots \\
& c_{9} & v_{9}
\end{array}\right]=\left[\begin{array}{ccc}
P_{0} & c_{1} & 88 \\
& c_{2} & 73 \\
\ldots & \ldots \\
& c_{9} & 78
\end{array}\right]
$$

The weight of each index was computed by the AHP method (Table 4).

Table 4. AHP-based weight index computation

\begin{tabular}{|c|c|c|c|c|c|c|c|c|c|c|c|}
\hline$O$ & $c_{1}$ & $c_{2}$ & $c_{3}$ & $c_{4}$ & $c_{5}$ & $c_{6}$ & $c_{7}$ & $c_{8}$ & $c_{9}$ & Weight & Consistency test \\
\hline$c_{1}$ & 1 & 2 & $1 / 4$ & $1 / 3$ & 2 & $1 / 6$ & $1 / 8$ & 3 & 5 & 0.066 & \multirow{9}{*}{$\begin{array}{c}\lambda_{\max }=9.952 \\
C I=0.019 \\
R I=1.45 \\
C R=0.082<0.1\end{array}$} \\
\hline$c_{2}$ & $1 / 2$ & 1 & $1 / 5$ & $1 / 2$ & 1 & $1 / 4$ & $1 / 8$ & 2 & 3 & 0.047 & \\
\hline$c_{3}$ & 4 & 6 & 1 & 2 & 3 & $1 / 2$ & $1 / 4$ & 3 & 3 & 0.132 & \\
\hline$c_{4}$ & 3 & 2 & $1 / 2$ & 1 & 3 & $1 / 4$ & $1 / 5$ & 3 & 2 & 0.084 & \\
\hline$c_{5}$ & $1 / 2$ & 1 & $1 / 3$ & $1 / 4$ & 1 & $1 / 6$ & $1 / 8$ & 3 & 4 & 0.051 & \\
\hline$c_{6}$ & 6 & 4 & 2 & 4 & 6 & 1 & $1 / 3$ & 8 & 6 & 0.215 & \\
\hline$c_{7}$ & 8 & 7 & 4 & 5 & 6 & 3 & 1 & 9 & 7 & 0.347 & \\
\hline$c_{8}$ & $1 / 3$ & $1 / 2$ & $1 / 3$ & $1 / 5$ & $1 / 4$ & $1 / 5$ & $1 / 9$ & 1 & 2 & 0.029 & \\
\hline$c_{9}$ & $1 / 4$ & $1 / 2$ & $1 / 4$ & $1 / 2$ & $1 / 4$ & $1 / 3$ & $1 / 8$ & 0.5 & 1 & 0.029 & \\
\hline
\end{tabular}

As shown in Table 4, the index weights are:

$\lambda=$

$(0.066,0.047,0.132,0.084,0.051,0.215,0.347,0.029,0.029$.

Obviously, the complaint rate and informatization level took up $21.5 \%$ and $34.7 \%$, respectively, in the overall grade. Together, the two indices accounted for over $50 \%$ of the overall grade, indicating that Company $\mathrm{H}$ attaches great importance to the complaint rate and informatization level of its 3PRL service provider.

Then, the extension superiority of Company $\mathrm{J}$ was calculated according to equations (4) (7) and the index weights. The calculation process and results are listed in Table 5 below.

Table 5. Evaluation of Company $\mathrm{J}$

\begin{tabular}{|c|c|c|c|c|c|c|c|c|c|}
\hline \multirow{2}{*}{$\begin{array}{c}\text { Evaluation } \\
\text { index }\end{array}$} & \multirow{2}{*}{ Weight } & \multicolumn{4}{|c|}{ Degree of correlation } & \multicolumn{4}{c|}{ Normalized degree of correlation } \\
\cline { 3 - 9 } & & $Z_{1}$ & $Z_{2}$ & $Z_{3}$ & $Z_{4}$ & $Z_{1}$ & $Z_{2}$ & $Z_{3}$ & $Z_{4}$ \\
\hline$c_{1}$ & 0.066 & 0.400 & -0.800 & -1.800 & -0.467 & 1.000 & -0.667 & -0.818 & -0.875 \\
\hline$c_{2}$ & 0.047 & -0.206 & 0.300 & -0.300 & -0.217 & -0.515 & 0.250 & -0.136 & -0.406 \\
\hline$c_{3}$ & 0.132 & 0.100 & -0.200 & -1.200 & -0.367 & 0.250 & -0.167 & -0.545 & -0.688 \\
\hline$c_{4}$ & 0.084 & 0.400 & -1.200 & -2.200 & -0.533 & 1.000 & -1.000 & -1.000 & -1.000 \\
\hline$c_{5}$ & 0.051 & -0.143 & 0.400 & -0.600 & -0.267 & -0.357 & 0.333 & -0.273 & -0.500 \\
\hline$c_{6}$ & 0.215 & 0.100 & -0.200 & -1.200 & -0.367 & 0.250 & -0.167 & -0.545 & -0.688 \\
\hline$c_{7}$ & 0.347 & 0.300 & -0.600 & -1.600 & -0.433 & 0.750 & -0.500 & -0.727 & -0.813 \\
\hline$c_{8}$ & 0.029 & 0.200 & -0.400 & -1.400 & -0.400 & 0.500 & -0.333 & -0.636 & -0.750 \\
\hline$c_{9}$ & 0.029 & -0.083 & 0.200 & -0.800 & -0.300 & -0.208 & 0.167 & -0.364 & -0.563 \\
\hline & & & & & 0.463 & -0.335 & -0.629 & -0.745 \\
\hline
\end{tabular}

The fitness calculation shows that $C\left(Z_{l}\right)=0.463$. This means Company $\mathrm{J}$ boasts excellent capability of reverse logistics. In other words, Company J can fulfil the reverse logistics demand of Company $\mathrm{H}$ in a satisfactory manner.

\section{CONCLUSIONS}

In this paper, the ESM is introduced to evaluate the capability of 3PRL providers. Firstly, an evaluation index system was constructed with nine influencing factors of provider capability, which fall on three levels: strength factor, service level and development potential. Then, the matterelement aggregate of the 3PRL provider was determined, together with its classical field and controlled field. Next, the weight of each index in the element aggregate was determined by the AHP, while the extension superiority was calculated.
The proposed evaluation method was verified through an empirical research on Company $\mathrm{H}$ and its 3PRL provider Company J. The results show that Company J enjoys excellent capability of reverse logistics. The application of the ESM transforms the fuzzy evaluation problem with multiple indices into a single-objective evaluation task and outputs quantitative results. The research findings shed new light on the evaluation of 3PRL providers.

\section{ACKNOWLEDGEMENT}

This paper is made possible thanks to the generous support from National Natural Science Foundation of China (Grant No.: 71602008, 71802021 and 71801013), Beijing Natural Science Foundation (Grant No.: 9184023), Beijing Social Science Fund Research Project (Grant No.: 16JDGLC032, 
17JDGLB011 and 18GLB022), and Fundamental Research Funds for the Central Universities (Grant No. FRF-OT-18012).

\section{REFERENCES}

[1] Gulotta TM, Guarino F, Mistretta M, Cellura M, Lorenzini G. (2018). Introducing exergy analysis in life cycle assessment: A case study. Mathematical Modelling of Engineering Problems 5(3): 139-145. https://doi.org/10.18280/mmep.050302

[2] Ma L. (2014). Research on the construction of evaluation index system for third-party reverse logistics suppliers. Logistics Technology (12): 77-79.

[3] Wu N. (2010). Research on evaluation index system of third-party reverse logistics suppliers under low carbon concept. Journal of Commercial Economics (32): 44-45. https://doi.org/10.3969/j.issn.1002-5863.2010.32.020

[4] Cao L. (2004). Home appliance industry of third-party reverse logistics provider evaluation system research. Logistics Sci-Tech (11): 103-120. https://doi.org/10.3969/j.issn.1002-3100.2015.11.029

[5] Yue H, Zhong XY, Ye HZ. (2015). Fuzzy evaluation research for the third-party reverse logistics enterprises. Soft Science 19(5): 39-42. https://doi.org/10.3969/j.issn.1001-8409.2005.05.011

[6] Liu QS, Wang XZ, Hou YZ. (2013). Research on thirdparty reverse logistics provider evaluation based on entropy. Science and Technology Management Research 33(10): 179-192. https://doi.org/10.3969/j.issn.10007695.2013.10.041
[7] Li J, Wang YM. (2015). Evaluation of third-party reverse logistics suppliers based on Fuzzy-QFD. Logistics Technology 10(2): 165-168. https://doi.org/10.3969/j.issn.1005152X.2015.10(2).035

[8] Chen KL. (2014). GI-TOPSIS's application in selection of reverse logistics service providers. China Business and Market 28(3): 39-48. https://doi.org/10.3969/j.issn.10078266.2014.03.007

[9] Li ZP, Jin YF. (2013). Application of TOPSIS in evaluation of third-party reverse logistics service providers. Logistics Technology 32(8): 179-181. https://doi.org/10.3969/j.issn.1005-152X.2013.08.058

[10] Du ZY, Yang SQ, Li JN. (2012). The application of extension superiority evaluation method in coal mine safety evaluation. Safety in Coal Mine 43(10): 221-224.

[11] Yang G. (2017). Application of extension superiority method in urban low carbon consumption evaluation. China Management Informationization 20(11): 110-111. https://doi.org/10.3969/j.issn.1673-0194.2017.11.053

[12] Jia P, Dong J. (2018). Extension goodness evaluation on performance index of BSC-based logistics service supply chain. Statistics \& Decision 34(3): 44-48. https://doi.org/10.13546/j.cnki.tjyjc.2018.03.009

[13] Liu YW. (2013). Strategy research on reverse logistics of cigarette packaging in Guangzhou. South China University of Technology.

[14] Shi Q. (2011). Research on problems of reverse logistics of Shijiazhuang Tobacco Logistics Centre. Hebei University of Science and Technology. 